\title{
Surgical pain is followed not only by spinal sensitization but also by supraspinal antinociception
}

\author{
O. H. G. Wilder-Smith, E. Tassonyi, C. Senly, Ph. Otten and L. Arendt-Nielsen
}

\begin{abstract}
Summary
Nociception can produce segmental spinal sensitization or descending supraspinal antinociception. We assessed both types of sensory change after surgery during isoflurane-nitrous oxide anaesthesia with or without fentanyl before nociception. Patients undergoing back surgery received fentanyl $3 \mu \mathrm{g} \mathrm{kg}^{-1}(n=15)$ or placebo $(n=15)$ before anaesthesia in a prospective, randomized, blinded study. Sensation, pain detection and tolerance thresholds to electrical stimulation were measured before operation at the arm, incision and herniated disc dermatomes (HDD) and $1,2,4,6,24 \mathrm{~h}$ and 5 days after operation, together with pain scores and patient-controlled morphine consumption (duration $24 \mathrm{~h}$ ). For segmental effects, thresholds were normalized to the thresholds at a distant dermatome (arm). Raw pain thresholds were increased after operation (fentanyl $>$ placebo) and were maximal at $4 \mathrm{~h}$ (pain tolerance in HDD: fentanyl $+5.2 \mathrm{~mA}(+62.7 \%)$, placebo, $+3.8 \mathrm{~mA}$ $(+44.2 \%) ; \quad P<0.05$ vs baseline for both). Normalized sensation thresholds decreased for placebo only (HDD/4 h:placebo, -1.8 ( $-44.8 \%)$, $P<0.05$; fentanyl, $+0.1(+5.5 \%)$ ns). All changes returned to baseline by $24 \mathrm{~h}$ except for the placebo group normalized HDD sensation (d5: placebo, $-2.4 \quad(-59.7) \%, \quad P<0.05 ; \quad$ fentanyl -0.1 $(-5.5 \%)$ ns). Pain scores and morphine consumption were similar. The study demonstrated both supraspinal analgesia and spinal sensitization after surgery. Fentanyl administration before operation augmented the former while decreasing the latter, and hence sensitization, especially if neuropathic, may particularly benefit from pre-emptive analgesia. (Br. J. Anaesth. 1996; 76: 816-821)
\end{abstract}

\section{Key words}

Pain, postoperative. Analgesia, postoperative. Analgesia, preemptive. Pain, threshold.

In an editorial discussing pain after surgery, Wall [1] noted, on the basis of animal experimentation, that nociception results in excitatory, segmental changes in central, spinal sensory processing (spinal sensitization). In animal experiments, it was found not only that opioids depress spinal sensitization, but that they were considerably more effective if given before rather than after nociception (pre-emptive analgesia) [2]. The clinical application of these findings has generated considerable debate, with the clinical reality of pre-emptive analgesia remaining controversial and the subject of intensive investigation $[3,4]$. In particular, it has proved difficult to demonstrate clinically significant effects on analgesic consumption and clinical pain measures [3, 4].

Groups [5, 6] working on intact animals and with more intense nociceptive stressors described opposing, inhibitory and supraspinal phenomena, such as "stress-induced analgesia (SIA)" or "diffuse noxious inhibitory controls (DNIC)". These groups used nociception that was longer-lasting or more intense, or both, than that of spinal sensitization models (e.g. being forced to swim in hot water vs short-lasting electrical stimulation), and found analgesia and hyposensitivity in sensory testing afterwards [7]. Similar sensory inhibition was elicited by stimulation of various brain regions ("stimulationinduced analgesia") [6]. SIA operates via descending, inhibitory encephalinergic, $\alpha$ adrenergic and NMDA systems [8].

Whether human surgery is associated with spinal sensitization or supraspinal inhibition has not been investigated in detail. Only few studies have examined the effect of pre-emptive analgesia on spinal sensitization; we have found none for SIA or DNIC. Richmond, Bromley and Woolf [9] and Collis and colleagues [10] found that mechanical secondary hyperalgesia was suppressed by preemptive morphine, but they did not give absolute thresholds. On a single occasion after operation, Lund, Hansen and Kehlet found an increased electric sensation threshold [11], while electric pain thresholds were decreased (and the nociceptive withdrawal reflex increased) in another study [12]. Both Willer, Bergeret and Gaudy [13] and Peters and colleagues [14] found increased thresholds in small postoperative studies. Thus data on postoperative changes in sensory processing with human surgery are scarce and contradictory.

The aim of this study was to investigate sensory processing after surgery using sensory skin thresholds. In particular, we were interested in

O. H. G. WILDER-SMITH, MB, CHB, MD, E. TASSONYI, MD, DSC, C. SENLY, MD (Department of Anaesthesiology); РH. ОTTEN, MD (Department of Neurosurgery); Geneva University Hospital, 24 rue Micheli-du-Crest, CH-1211 Geneva 14, Switzerland. L. ARENDT-NIELSEN, PHD, Centre for Sensory-Motor Interaction, Laboratory for Experimental Pain Research, University of Aalborg, Fredrik Bajersvej 7D, DK-9220 Aalborg E, Denmark. Accepted for publication: February 7, 1996.

Correspondence to O. H. G. W.-S. 
detecting and differentiating between generalized (e.g. supraspinal inhibition) and segmental (e.g. spinal sensitization) changes in sensory function. We also determined the effect of pre-emptive fentanyl analgesia on changes in sensory processing which might be present after surgery. Finally, we determined if altered sensory processing affects clinical measures of pain (analgesic consumption, pain scores).

\section{Patients and methods}

We studied 30 ASA I and II patients, undergoing elective herniated intervertebral disc surgery. The study design was prospective, randomized and double-blind. Institutional review board and Ethics Committee approval were obtained, and all patients gave informed written consent.

Patients were instructed on threshold measurement, pain verbal rating scores (VRS) and use of a patient-controlled analgesia (PCA) pump. They received no premedication on the morning of operation. Before insertion of a venous cannula, pain verbal rating scores $(0=$ no pain; $10=$ worst pain imaginable) for the back and affected leg dermatome and sensation, pain detection and pain tolerance thresholds were determined. Thresholds were obtained using constant skin current stimulation (Digistim, Biometer A/S, Copenhagen/DK; tetanic stimulation at $100 \mathrm{~Hz}, 0.2 \mathrm{~ms}$ square wave pulses) via self-adhesive electrodes $3 \mathrm{~cm}$ apart. Measurements were carried out in the middle of the nerve root dermatome most affected by disc prolapse; on the flanks at the height of the back incision (T12-L1 dermatome), ipsilateral and contralateral to the side of the involved nerve root; and the proximal arm contralateral to the involved nerve root (C8-T1). Care was taken not to stimulate major nerves, and measurements were separated by $5 \mathrm{~min}$. The three end-points, measured successively in a run, were the averages of the three runs.

Five minutes before induction of anaesthesia, patients received a blinded short infusion $(0.9 \% \mathrm{NaCL} 100 \mathrm{ml})$ containing either placebo (placebo group) or fentanyl $3 \mu \mathrm{g} \mathrm{kg}^{-1}$ (fentanyl group). Anaesthesia was induced with thiopentone $5 \mathrm{mg} \mathrm{kg}^{-1}$, followed by vecuronium $0.1 \mathrm{mg} \mathrm{kg}^{-1}$. After tracheal intubation, anaesthesia was maintained with isoflurane and $66 \%$ nitrous oxide in oxygen. No other supplementation was given and the interventions usually lasted less than $1 \mathrm{~h}$.

Thirty minutes after extubation, morphine by patient-controlled analgesia (PCA) was started (loading bolus $60 \mu \mathrm{g} \mathrm{kg}^{-1}$, PCA bolus $25 \mu \mathrm{g} \mathrm{kg}^{-1}$; lock-out interval $8 \mathrm{~min}$ in recovery room, $15 \mathrm{~min}$ on ward; background infusion $15 \mu \mathrm{g} \mathrm{kg}^{-1} \mathrm{~h}^{-1}$ during the first $2 \mathrm{~h}$ in the recovery room). No other analgesics were given. Threshold and VRS measures, as before, and cumulative morphine consumption were assessed 1, 2, 4, 6 and $24 \mathrm{~h}$ after extubation. PCA morphine was discontinued $24 \mathrm{~h}$ after operation. Threshold and VRS values were obtained 5 days after operation. Observer sedation rating scores $(5=$ wide awake, $1=$ unrousable) were also noted at measurement times.
Based on the data of Lautenbacher and Rollman [15], the study was designed to have the power to detect a difference of $20 \%$ in sensation thresholds. To separate generalized from segmental (spinal) effects on thresholds, normalized (or relative) and raw thresholds were analysed. Thresholds were normalized relative to the arm $[9,10]$. Thus normalized thresholds were calculated by dividing para-incisional and affected dermatome threshold values by the respective arm threshold values. All statistical analysis was performed using the software package Statistica for Windows (release 4.5, Statsoft Inc, 2325 East 13th Street, Tulsa, OK 74104, USA). Patient data were compared by unpaired $t$ test. Analysis of thresholds, pain VRS or sedation scores and cumulative morphine consumption was by repeated measures ANCOVA, with the preoperative baseline values acting as covariant. Post hoc testing was by Tukey's honest significant difference test. Statistical significance was assumed if $P<0.05$.

\section{Results}

The two groups were comparable (table 1), with similar preoperative (baseline) pain VRS and threshold values. There were no significant differences between groups for back or leg pain VRS, cumulative morphine consumption or observer sedation scores (table 2).

Raw thresholds were increased after operation (table 3, fig. 1). In both groups mainly the 4-h measurements of affected dermatome pain thresholds were increased significantly compared with baseline. Combining all thresholds, the fentanyl group values were significantly higher than the placebo values $(P$ $<0.02)$. Overall, the thresholds at different measurement sites and the sensation, pain detection and pain tolerance thresholds were significantly different $(P<0.008$ and 0.00001 , respectively). Arm site thresholds overall were significantly lower than for the para-incisional site $(P<0.024)$, with no significant difference between para-incisional and affected dermatome thresholds. All three threshold test types differed from each other $(P<0.0001)$. For thresholds overall, values at $24 \mathrm{~h}$ and 5 days were generally lower than the preceding postoperative values $(P<0.0001)$. Baseline thresholds significantly affected subsequent values $(P<0.0001)$.

For normalized thresholds taken together (fig. 2), the groups or measurement sites did not differ. Only in the placebo group were sensation thresholds in the affected dermatome significantly lower than baseline at 4 and $6 \mathrm{~h}$ and 5 days after operation. Overall, the three threshold test types continued to be different $(P<0.00001)$, and day 5 threshold values together differed from those at 1,2 and $24 \mathrm{~h}$ after operation. For sensation thresholds alone, the values in the placebo group were significantly lower than in the fentanyl group $(P<0.003)$ overall. Baseline values

Table 1 Patient data (mean (SD or range))

\begin{tabular}{lllll}
\hline & Age $(\mathrm{yr})$ & Weight $(\mathrm{kg})$ & Height $(\mathrm{cm})$ & Sex $(M: F)$ \\
\hline Placebo & $47.8(24-64)$ & $75.0(13.4)$ & $171.9(9.2)$ & $10: 5$ \\
Fentanyl & $14.1(27-62)$ & $74.3(14.6)$ & $169.5(20.6)$ & $12: 3$ \\
\hline
\end{tabular}


Table 2 Pain, sedation and morphine consumption. VRS = Verbal rating score for leg (L) or back (B) pain; OSS = observer sedation score; morphine = cumulative morphine consumption. Values for VRS and OSS are median (quartile range); cumulative morphine consumption values are mean (SD). BL = Baseline.

\begin{tabular}{|c|c|c|c|c|c|c|c|}
\hline & \multicolumn{6}{|c|}{ Time after operation } & \multirow[b]{2}{*}{5 days } \\
\hline & $\mathrm{BL}$ & $1 \mathrm{~h}$ & $2 \mathrm{~h}$ & $4 \mathrm{~h}$ & $6 \mathrm{~h}$ & $24 \mathrm{~h}$ & \\
\hline \multicolumn{8}{|l|}{ VRS/L } \\
\hline Placebo & $\begin{array}{l}0 \\
(0-2.5)\end{array}$ & $\begin{array}{l}2 \\
(0-4)\end{array}$ & $\begin{array}{l}2 \\
(0-3.5)\end{array}$ & $\begin{array}{l}1 \\
(0-4.5)\end{array}$ & $\begin{array}{l}0 \\
(0-1.5)\end{array}$ & $\begin{array}{l}1 \\
(0-1.5)\end{array}$ & $\begin{array}{l}0.5 \\
(0-2.0)\end{array}$ \\
\hline Fentanyl & 1 & 2 & 0 & 0 & 0 & 0 & 2 \\
\hline \multicolumn{8}{|l|}{ VRS/B } \\
\hline Placebo & $\begin{array}{l}0 \\
(0-0.5)\end{array}$ & $\begin{array}{l}5 \\
(2.5-5.5)\end{array}$ & $\begin{array}{l}3 \\
(2-4)\end{array}$ & $\begin{array}{l}4 \\
(2-5)\end{array}$ & $\begin{array}{l}2.5 \\
(0.5-3)\end{array}$ & $\begin{array}{l}2.5 \\
(1-3.5)\end{array}$ & $\begin{array}{l}1 \\
(0.5-1)\end{array}$ \\
\hline Fentanyl & $\begin{array}{l}0 \\
(0-1)\end{array}$ & $\begin{array}{l}4 \\
(1.5-5.5)\end{array}$ & $\begin{array}{l}3 \\
(1.5-4.5)\end{array}$ & $\begin{array}{l}3 \\
(1.5-4.5)\end{array}$ & $\begin{array}{l}3 \\
(0-4)\end{array}$ & $\begin{array}{l}1 \\
(0-2.5)\end{array}$ & $\begin{array}{l}1 \\
(0-2)\end{array}$ \\
\hline \multicolumn{8}{|l|}{ Oss } \\
\hline Placebo & $\begin{array}{l}5 \\
(5-5)\end{array}$ & $\begin{array}{l}4 \\
(3-4)\end{array}$ & $\begin{array}{l}4 \\
(4-5)\end{array}$ & $\begin{array}{l}5 \\
(5-5)\end{array}$ & $\begin{array}{l}5 \\
(4-5)\end{array}$ & $\begin{array}{l}5 \\
(5-5)\end{array}$ & $\begin{array}{l}5 \\
(5-5)\end{array}$ \\
\hline Fentanyl & $\begin{array}{l}5 \\
(5-5)\end{array}$ & $\begin{array}{l}4 \\
(3-4)\end{array}$ & $\begin{array}{l}4 \\
(4-4.5)\end{array}$ & $\begin{array}{l}5 \\
(4-5)\end{array}$ & $\begin{array}{l}5 \\
(4-5)\end{array}$ & $\begin{array}{l}5 \\
(5-5)\end{array}$ & $\begin{array}{l}5 \\
(5-5)\end{array}$ \\
\hline \multicolumn{8}{|c|}{ Morphine (mg) } \\
\hline Placebo & 0 & $\begin{array}{l}6.3 \\
(2.3)\end{array}$ & $\begin{array}{l}9.8 \\
(4.1)\end{array}$ & $\begin{array}{l}15.3 \\
(6.2)\end{array}$ & $\begin{array}{l}18.5 \\
(7.2)\end{array}$ & $\begin{array}{l}33.7 \\
(13.5)\end{array}$ & \\
\hline Fentanyl & 0 & $\begin{array}{l}6.4 \\
(1.7)\end{array}$ & $\begin{array}{l}10.3 \\
(5.3)\end{array}$ & $\begin{array}{l}16.8 \\
(9.2)\end{array}$ & $\begin{array}{l}21.1 \\
(12.4)\end{array}$ & $\begin{array}{l}38.0 \\
(29.8)\end{array}$ & \\
\hline
\end{tabular}

Table 3 Absolute threshold values. Values are (mean (SD)) mA, times (except control) are postoperative. C $=$ Incision dermatome contralateral to affected side, $\mathrm{I}=$ incision dermatome ipsilateral to affected side, $\mathrm{D}=$ dermatome affected most by nerve compression caused by disc prolapse. ${ }^{\star} P<0.05$ vs baseline; $\dagger P<0.05$ vs day 5 value. Only the differences at individual times for a given threshold type and dermatome are marked; for other results, see text.

\begin{tabular}{|c|c|c|c|c|c|c|c|}
\hline & \multirow[b]{2}{*}{ Control } & \multicolumn{6}{|c|}{ Time after operation } \\
\hline & & $1 \mathrm{~h}$ & $2 \mathrm{~h}$ & $4 \mathrm{~h}$ & $6 \mathrm{~h}$ & $24 \mathrm{~h}$ & 5 days \\
\hline \multicolumn{8}{|c|}{ Sensation thresholds } \\
\hline Arm, placebo & $0.8(0.7)$ & $2.3(2.4)$ & $2.7(1.7)$ & $2.0(1.5)$ & $2.1(1.4)$ & $2.1(1.7)$ & $0.8(1.1)$ \\
\hline Arm, fentanyl & $1.0(0.9)$ & $2.1(1.3)$ & $2.5(2.2)$ & $1.9(1.2)$ & $1.7(0.9)$ & $1.5(1.3)$ & $0.4(0.5)$ \\
\hline C, placebo & $0.8(0.5)$ & $2.2(1.5)$ & $2.3(1.6)$ & $1.9(1.0)$ & $2.1(1.3)$ & $2.1(1.0)$ & $0.7(0.8)$ \\
\hline C, fentanyl & $1.1(0.8)$ & $3.5(2.4)$ & $3.7(1.9)$ & $3.0(1.9)$ & $2.6(2.0)$ & $2.9(2.8)$ & $0.5(0.4)$ \\
\hline I, placebo & $0.9(0.5)$ & $2.4(2.1)$ & $2.2(1.4)$ & $2.1(2.1)$ & $2.5(1.8)$ & $2.2(1.1)$ & $0.6(0.5)$ \\
\hline I, fentanyl & $1.2(0.8)$ & $2.7(2.1)$ & $3.0(1.7)$ & $2.6(1.5)$ & $2.4(1.2)$ & $1.7(1.1)$ & $0.5(0.4)$ \\
\hline $\mathrm{D}$, placebo & $1.9(2.1)$ & $3.7(2.4)$ & $3.3(2.7)$ & $3.5(2.4)$ & $3.3(2.5)$ & $2.9(2.7)$ & $1.0(1.3)$ \\
\hline $\mathrm{D}$, fentanyl & $1.4(1.1)$ & $3.2(2.4)$ & $3.2(2.1)$ & $3.2(2.8)$ & $2.5(1.5)$ & $1.8(1.4)$ & $0.9(0.9)$ \\
\hline \multicolumn{8}{|c|}{ Pain detection thresholds } \\
\hline Arm, placebo & $5.3(3.5)$ & $6.4(4.1)$ & $6.6(4.6)$ & $6.2(3.5)$ & $5.4(2.9)$ & $6.3(3.3)$ & $2.8(3.7)$ \\
\hline Arm, fentanyl & $4.9(3.2)$ & $7.9(3.5)$ & $8.1(3.3)$ & $7.0(3.2)$ & $6.3(3.4)$ & $5.6(3.2)$ & $3.6(3.1)$ \\
\hline $\mathrm{C}$, placebo & $5.1(3.7)$ & $7.3(3.6)$ & $7.7(3.9)$ & $7.5(3.3) \dagger$ & $7.4(3.8) \dagger$ & $7.4(4.1) \dagger$ & $2.8(2.9)$ \\
\hline C, fentanyl & $5.4(3.1)$ & $9.5(4.0)$ & $8.3(3.2)$ & $8.5(3.4)$ & $7.8(3.8)$ & $6.8(4.2)$ & $3.1(3.5)$ \\
\hline I, placebo & $5.2(4.0)$ & $8.4(5.0) \dagger$ & $7.9(5.1) \dagger$ & $7.7(4.9) \dagger$ & $7.6(4.2) \dagger$ & $8.3(4.1) \dagger$ & $2.6(3.3)$ \\
\hline I, fentanyl & $6.1(3.1)$ & $8.0(3.4)$ & $9.0(3.5)$ & $8.0(3.3)$ & $8.1(3.5)$ & $6.2(3.6)$ & $2.6(2.2)$ \\
\hline $\mathrm{D}$, placebo & $5.7(5.2)$ & $8.0(5.1)$ & $7.8(5.1)$ & $8.5(5.2) \dagger$ & $9.3(5.2) \dagger$ & $6.9(4.7)$ & $2.9(3.5)$ \\
\hline $\mathrm{D}$, fentanyl & $4.8(2.8)$ & $8.4(4.0)$ & $8.0(3.8)$ & $9.6(6.2) \dagger \ddagger$ & $7.0(3.1)$ & $6.6(3.0)$ & $3.7(3.0)$ \\
\hline \multicolumn{8}{|c|}{ Pain tolerance thresholds } \\
\hline Arm, placebo & $9.7(4.2)$ & $11.6(5.0) \dagger$ & $10.4(5.3)$ & $10.6(4.3) \dagger$ & $10.2(4.0) \dagger$ & $9.4(3.7)$ & $5.2(4.4)^{\star}$ \\
\hline Arm, fentanyl & $8.9(4.0)$ & $12.6(3.2) \dagger$ & $13.1(3.8) \dagger$ & $11.7(4.4) \dagger$ & $10.4(5.1)$ & $8.8(3.8)$ & $5.9(4.6)$ \\
\hline C, placebo & $9.6(5.1)$ & $11.6(3.8) \dagger$ & $12.2(4.4) \dagger$ & $12.8(4.4) \dagger$ & $12.1(4.8) \dagger$ & $11.1(4.9) \dagger$ & $5.4(4.7)$ \\
\hline C, fentanyl & $9.0(3.1)$ & $13.9(4.3) \dagger$ & $13.5(4.1) \dagger$ & $14.0(4.4) t^{\star}$ & $13.0(5.4) \dagger$ & $10.1(5.1) \dagger$ & $5.6(5.5)$ \\
\hline I, placebo & $9.3(4.7)$ & $11.7(5.7) \dagger$ & $12.5(5.8) \dagger$ & $11.6(5.2) \dagger$ & $11.8(5.0) \dagger$ & $12.1(4.5) \dagger$ & $4.9(4.3)$ \\
\hline I, fentanyl & $9.5(3.4)$ & $15.0(5.8) \dagger$ & $13.7(4.4) \dagger$ & $13.3(4.3) \dagger$ & $13.6(3.8) \dagger$ & $9.9(4.1)$ & $5.7(4.8)$ \\
\hline $\mathrm{D}$, placebo & $8.6(6.0)$ & $11.4(5.8) \dagger$ & $11.4(6.0) t$ & $12.4(6.3) t^{\star}$ & $13.2(6.2) t^{\star}$ & $10.4(5.7) t$ & $5.1(4.9)$ \\
\hline $\mathrm{D}$, fentanyl & $8.3(4.3)$ & $12.6(5.5)$ & $12.6(5.1)$ & $13.5(8.0) \dagger^{\star}$ & $11.0(6.0)$ & $9.6(4.7)$ & $7.2(6.3)$ \\
\hline
\end{tabular}

influenced normalized thresholds only up to $4 \mathrm{~h}$ after operation.

\section{Discussion}

In this study, surgery was associated with generalized sensory inhibition and segmental sensitization in the immediate postoperative period.
Changes in sensory processing generally returned to baseline within $24 \mathrm{~h}$ after operation. Compared with placebo, pre-emptive fentanyl inhibited segmental sensitization, and was accompanied by increased generalized sensory inhibition. These differences between groups were not significantly reflected in clinical measures such as pain scores or morphine consumption in our study, indicating the importance 


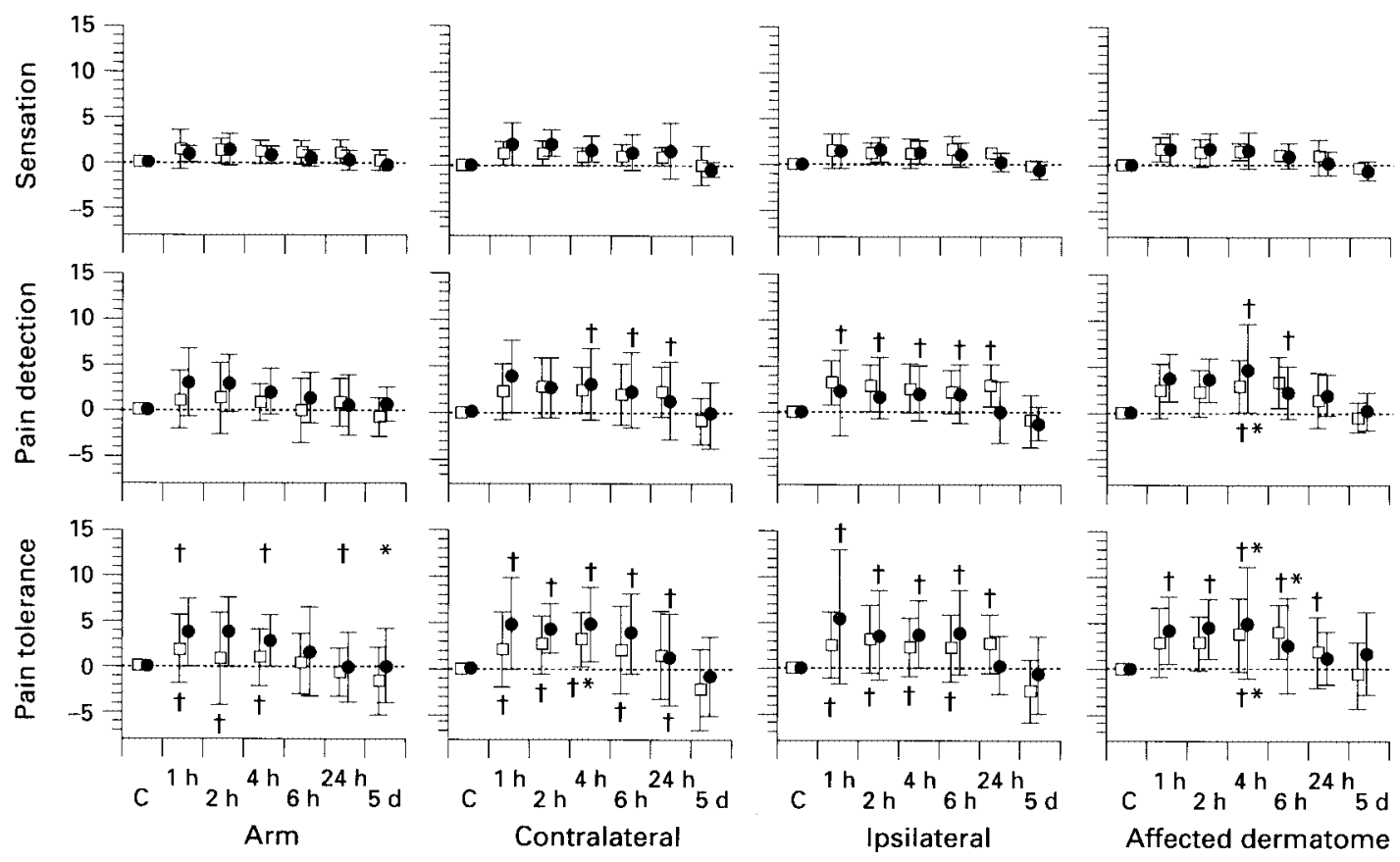

Figure 1 Changes from baseline of raw sensory thresholds (mean, SD mA). The dermatomes tested (X axis) and the types of threshold tests (Y axis) are indicated. ${ }^{\star} P<0.05$ vs baseline; $\dagger P<0.05$ vs day 5 value. The significances for the placebo group are marked above the zero line, those for the fentanyl group, below. Only differences at individual times within a given graph are marked (for other results, see text).

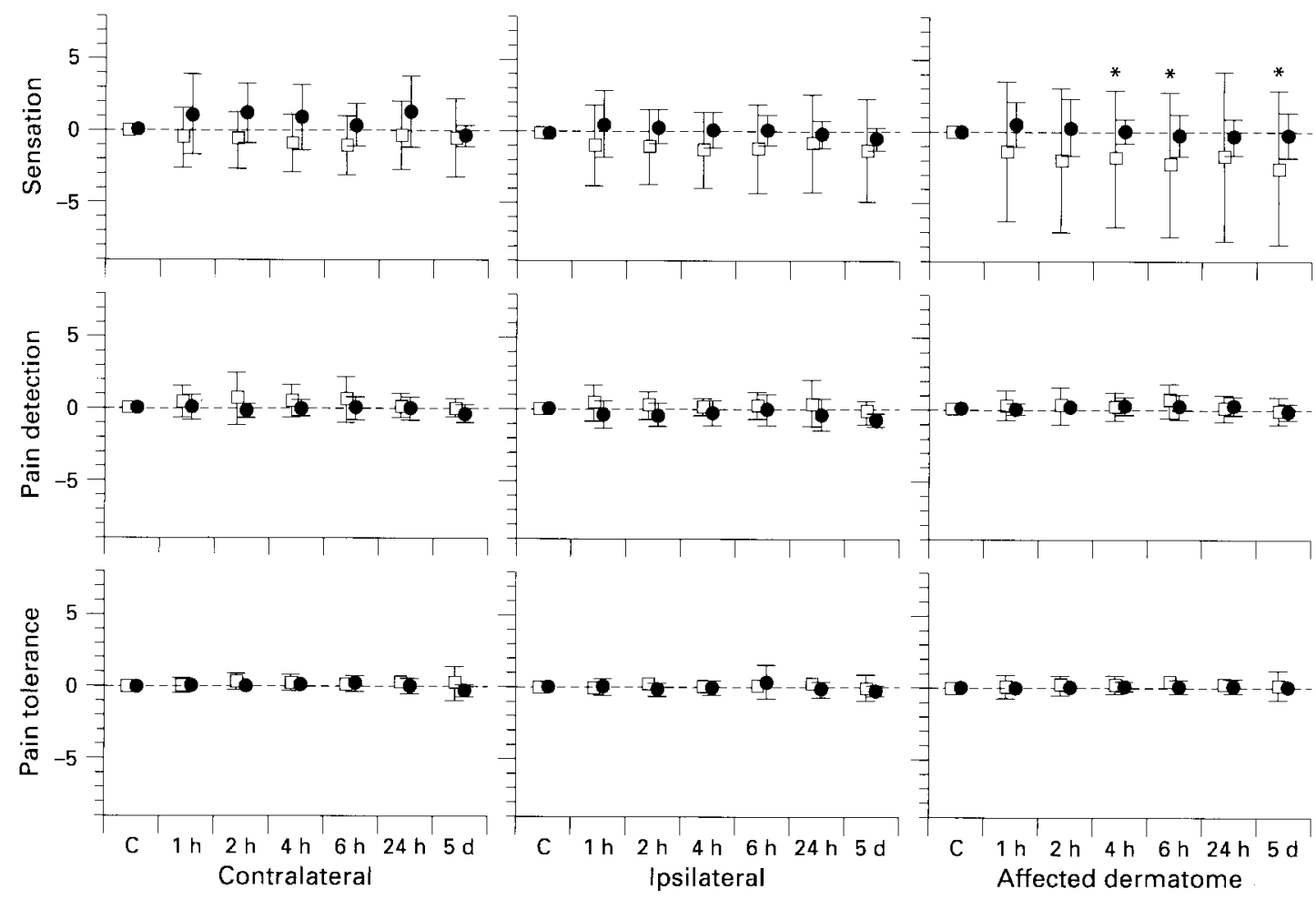

Figure 2 Changes from baseline of normalized sensory thresholds in arbitrary units (mean, SD rations). The dermatomes tested ( $\mathrm{X}$ axis) and the types of threshold tests ( $\mathrm{Y}$ axis) are indicated. ${ }^{\star} P<0.05 v$ s baseline. The significances for the placebo group are marked above the zero line, those for the fentanyl group, below. Only differences at individual times within a given graph are marked (for other results, see text).

of sensory testing in assessing nociception after operation.

Measurement of pain thresholds by cutaneous electrical stimulation is easy to use and well validated
[15]. While electrical thresholds do not represent a pure nociceptive activation, but a mixed nerve fibre population response, we consider its use acceptable in the surgical context because surgery also involves 
a mixed response. Additionally, use of the more complex equipment necessary for pure nociceptive stimulation (lasers, Peltier elements) is difficult if not impossible on the ward. Possible sensitization by threshold measurements was minimized by spacing the measures, doing only three runs and stopping on just reaching the pain tolerance threshold. In common with other groups $[9,10]$ we normalized thresholds relative to the arm. Because the arm was far away from the surgical site, it was unlikely to be affected by segmental or spinal sensory changes after operation, while still being subject to any generalized or supraspinal changes, making possible separation of the two types of altered sensory processing.

Extraneous factors which may have influenced thresholds include increased reaction times and analgesic or anaesthetic drugs. In order to decrease the effect of reaction times, electric stimulation was increased very slowly (approximately $0.1 \mathrm{~mA} \mathrm{~s}^{-1}$ ). In addition, sedation scores were similar between groups throughout, and were normal by $4 \mathrm{~h}$ after operation. Isoflurane in subanaesthetic concentrations has no effect on pain detection thresholds [16]; nitrous oxide may increase pain detection thresholds for up to $30 \mathrm{~min}$ after its discontinuation [17]. Opioids such as morphine or fentanyl have no direct effects on sensation or pain detection thresholds [18]. The effects on pain tolerance thresholds are most visible if the stimulus is long or repeated, and are small for tolerance to single pain stimuli [18]. Thus direct drug effects on the thresholds can be expected to have been minimal, particularly with regard to sensation and pain detection thresholds.

Patients titrated themselves to similar pain levels in the groups using PCA morphine. The lack of difference in morphine consumption may primarily result from group size, or because back surgery is only moderately painful, or both. The group size had the statistical power to detect a difference of $50 \%$ in morphine consumption at $24 \mathrm{~h}$ between the groups. These results suggest that sensory testing may be more sensitive in the assessment of change after operation than clinical measures such as morphine consumption or pain scores. The relevance of such sensory changes for long-term outcome needs investigation.

We have found no other studies which have systematically investigated sensory thresholds after surgery in humans with regard to spinal sensitization or supraspinal inhibition. Richmond, Bromley and Woolf [9] and Collis and colleagues [10], studying pre-emptive morphine for hysterectomy, found postoperative differential (i.e. forearm-abdomen) pain detection thresholds to mechanical stimulation to be smaller in the pre-emptive group, suggesting less spinal sensitization. There was no difference in sensation thresholds. No preoperative measures were given, however, making further interpretation difficult. The absence of threshold values in a dermatome distant to the surgical site precludes conclusions about the presence or absence of generalized sensory inhibition. The mainly raised thresholds in the studies of Lund, Hansen and Kehlet [11], Dahl and colleagues [12], Willer, Bergeret and Gaudy [13] and Peters and colleagues
[14] have already been mentioned. Their results are difficult to compare with ours, as they involved different times, sites and methods.

The increased sensory thresholds after operation demonstrated in our study are likely to be the result of descending central inhibitory controls elicited by the nociception of surgery (e.g. SIA or DNIC [5-8]. Sensory inhibition in our study was generalized and detectable up to $24 \mathrm{~h}$ after operation. DNIC operates on convergent neurones and generally fades shortly after the conditioning stimulus [19], making it a less likely mechanism in this case than SIA. SIA is supported further by the fact that while DNIC is depressed by opioids [20], SIA has been described as being augmented by opioid supplementation [21, 22]. However, SIA mechanisms are complex, involving both opioid and non-opioid pathways, possibly mutually antagonistic [23], and a final understanding must await more complete elucidation of this phenomenon. The only possible alternative explanation could be the level adaptation theory, which postulates that pain thresholds change because of resetting of the reference point for pain thresholds [14]. This theory is unlikely to explain the shift in sensation thresholds also seen in our study, but definite differentiation would depend on measurement of the nociceptive withdrawal reflex [14] not performed in our study. It should however be remembered that the withdrawal reflex is affected by changes both in the sensory and motor system. Segmental spinal sensitization caused by nociception is also well described in the literature for animal models $[2,3]$. Studies confirming spinal sensitization after nociception in human volunteers have now been performed [24], but formal clinical studies are still lacking, as are studies of the long-term implications of such changes for outcome after surgery.

The fentanyl supplemented group showed more supraspinal antinociception after operation than the placebo group. This would suggest that, as shown experimentally [21,22], opioids act synergistically with descending inhibitory systems, providing another rationale for pre-emptive analgesia. Opioids are effective at preventing and treating spinal sensitization, particularly of the nociceptive system [4], as confirmed by our study. The fentanyl group showed no segmental sensitization; in the placebo group it was visible only for the somatosensory system. Expression of nociceptive system sensitization in the placebo group may have been suppressed by morphine analgesia in the context of only moderately nociceptive surgery, leaving only somatosensory sensitization visible [25]. This possibility needs further study using more painful surgical interventions and larger patient groups. In the placebo group, segmental sensitization was still present compared with the fentanyl group in the affected dermatome 5 days after operation, at a time when all other sensory changes had reverted to normal. This suggests that under special circumstances (e.g. the presence before surgery of neuropathic pain or sensitization associated with nerve damage), changes in sensory processing can persist long-term with poorly blocked pre- or intraoperative 
nociception, as also suggested by the amputation studies of Bach, Noreng and Tjellden [26]. Further studies are needed to confirm this.

\section{References}

1. Wall PD. The prevention of postoperative pain. Pain 1988; 33: $289-290$.

2. Woolf CJ, Wall PD. Morphine-sensitive and morphineintensitive actions of C-fibre input on the rat spinal cord. Neuroscience Letters 1986; 64: 221-225.

3. Woolf CJ, Chong MS. Pre-emptive analgesia: treating postoperative pain by preventing the establishment of central sensitisation. Anesthesia and Analgesia 1993; 77: 362-379.

4. Coderre TJ, Katz J, Vaccarino AL, Melzack R. Contribution of central neuroplasticity to pathological pain: review of clinical and experimental evidence. Pain 1993; 52: 259-285.

5. Le Bars D, Dickenson AH, Besson JC. Diffuse noxious inhibitory controls (DNIC). I. Effects on dorsal horn convergent neurones in the rat. Pain 1979; 10: 283-304.

6. Termann GW, Penner ER, Liebeskind JC. Stimulationproduced and stress-induced analgesia: cross-tolerance between opioid forms. Brain Research 1986; 372: 167-171.

7. Kelly DD (editor). Stress-induced analgesia. Annals of the New York Academy of Sciences 1986; 467: 1-449.

8. Sternberg WF, Liebeskind JC. The analgesic response to stress: genetic and gender considerations. European fournal Anaesthesiology 1995; 12 (Suppl. 10): 14-17.

9. Richmond CE, Bromley LM, Woolf CJ. Preoperative morphine pre-empts postoperative pain. Lancet 1993; 342: 73-75.

10. Collis R, Brandner B, Bromley LM, Woolf CJ. Is there any clinical advantage of increasing the pre-emptive dose of morphine or combining pre-incisional with postoperative morphine administration? British Fournal of Anaesthesia 1995; 74: 396-399.

11. Lund C, Hansen OB, Kehlet H. Effect of surgery on sensory threshold and somatosensory evoked potentials after skin stimulation. British fournal of Anaesthesia 1990; 65: 173-176.

12. Dahl JB, Erichsen CJ, Fuglsang-Frederiksen A, Kehlet H. Pain sensation and nociceptive reflex excitability in surgical patients and human volunteers. British fournal of Anaesthesia 1992; 69: 117-121.

13. Willer JC, Bergeret S, Gaudy JH. Epidural morphine strongly depresses nociceptive flexion reflexes in patients with postoperative pain. Anesthesiology 1985; 63: 675-680.
14. Peters ML, Schmidt AJM, Van den Hout MA, Koopmans R, Sluijter $M$. Chronic back pain, acute postoperative pain and the activation of diffuse noxious inhibitory controls. Pain 1992; 50: 177-187.

15. Lautenbacher S, Rollman GB. Sex differences in responsiveness to painful and non-painful stimuli are dependent upon the stimulation method. Pain 1993; 53: 255-264.

16. Tomi K, Mashimoto T, Tashiro C, Yagi M, Pak M, Nishimura S, Nishimura $M$, Yoshiya I. Alterations in pain threshold and psychomotor response associated with subanaesthetic concentrations of inhalation anaesthetics in humans. British Fournal of Anaesthesia 1993; 70: 684-686.

17. Ramsay DS, Brown AC, Woods SC. Acute tolerance to nitrous oxide in humans. Pain 1992; 51: 367-373.

18. van der Burght $M$, Rasmussen SE, Arendt-Nielsen L, Bjerring P. Morphine does not affect laser induced warmth and pin prick thresholds. Acta Scandinavica Anaesthesiologica 1994; 38: 161-164.

19. Bouhassira D, Bing Z, Le Bars D. Studies of the brain structures involved in diffuse noxious inhibitory controls in the rat: the rostral ventromedial medulla. Fournal of Physiology (London) 1993; 463: 667-687.

20. Le Bars D, Willer JC, De Broucker T. Morphine blocks descending pain inhibitory controls in humans. Pain 1992; 48: $13-20$.

21. Woolfolk DR, Holtzman SG. Restraint stress potentiates analgesia induced by $5^{\prime}-\mathrm{N}$-ethylcarboxamidoadenosine: comparison with morphine. European fournal of Pharmacology 1993; 239: 177-182.

22. Gogas KR, Presley RW, Levine JD, Basbaum AI. The antinociceptive action of supraspinal opioids results from an increase in descending inhibitory control: correlation of nociceptive behaviour and c-fos expression. Neuroscience 1991; 42: 617-628.

23. Grisel JE, Fleshner M, Watkins LR, Maier SF. Opioid and nonopioid interactions in two forms of stress-induced analgesia. Pharmacology, Biochemistry and Behavior 1993; 45: 161-172.

24. Brennum, J, Dahl JB, Moiniche S, Arendt-Nielsen L. Quantitative sensory examination of epidural anaesthesia and analgesia in man: effects of pre- and post-traumatic morphine on hyperalgesia. Pain 1994; 59: 261-271.

25. Herrero JF, Headley PM. Sensitization of spinal neurons by non-noxious stimuli in the awake but not anesthestized state. Anesthesiology 1995; 82: 267-275.

26. Bach S, Noreng MF, Tjellden NU. Phantom limb pain in amputees during the first 12 months following limb amputation, after preoperative lumbar epidural blockade. Pain 1988; 33: 297-301. 